\title{
Efeitos tempo, parturição e quantum no Brasil: indicadores de período e evidências empíricas
}

\author{
Adriana de Miranda-Ribeiro* \\ Eduardo Luiz Gonçalves Rios-Neto ** \\ José Alberto Magno de Carvalho***
}

O presente artigo tem como objetivo estimar e comparar diferentes indicadores de fecundidade de período, com enfoque naqueles que corrigem distorções causadas na taxa de fecundidade total (TFT) observada em determinado período, a fim de criar e avaliar novas possibilidades de análise da fecundidade no Brasil. São apresentadas séries de TFT, TFT PPR, PATFR, PATFR $_{\text {ajustada }}(\mathrm{K}-\mathrm{O}$ ), PDTFR e PADTFR, bem como as séries históricas dos efeitos tempo e parturição e da idade média da fecundidade. Foram utilizados os bancos de dados sobre histórias de nascimentos, obtidos a partir das edições de 1980, 1991 e 2000 do Censo Demográfico brasileiro. Os resultados mostram que, no Brasil, a transição da fecundidade foi acompanhada, durante praticamente todo o período de análise, por um efeito tempo negativo e um efeito parturição positivo, que atuaram no sentido de inflar a fecundidade observada. No futuro próximo, a fecundidade observada no Brasil deverá ser diminuída, principalmente pela ação do efeito tempo positivo.

Palavras-chave: Fecundidade. Efeito tempo. Quantum. História de nascimentos. Brasil.

\footnotetext{
* Doutora, demógrafa, pesquisadora em Ciência e Tecnologia da Fundação João Pinheiro/MG (ricaadri@gmail.com; adriana. ribeiro@fjp.mg.gov.br).

** PhD, demógrafo, professor titular e pesquisador do Centro de Desenvolvimento e Planejamento Regional - Cedeplar/ Universidade Federal de Minas Gerais - UFMG (eduardo@cedeplar.ugmg.br).

*** Doutor, demógrafo, professor emérito da Universidade Federal de Minas Gerais - UFMG, pesquisador do Centro de Desenvolvimento e Planejamento Regional - Cedeplar/UFMG e diretor executivo da Fundação Instituto de Pesquisas Econômicas, Administrativas e Contábeis de Minas Gerais - Ipead/Face/UFMG (carvalho@cedeplar.ufmg.br).
} 


\section{Introdução}

Os debates acerca de medidas de fecundidade de período e de coorte têm sido frequentes na literatura nas últimas décadas. É fato que, entre as medidas de fecundidade conhecidas, não existe aquela que seja completa ou que traduza todas as nuances do comportamento reprodutivo humano. A preocupação que, outrora, esteve focada no crescimento populacional tem se voltado para os problemas que baixos níveis de crescimento ou decrescimento populacional prolongados - decorrentes dos baixos níveis de fecundidade - podem causar em uma população.

À medida que a fecundidade diminui e as mudanças passam a ocorrer em ritmo mais lento, novas dimensões assumem papel importante nas análises sobre a fecundidade. Os indicadores de período refletem a interação entre os componentes tempo, parturição e quantum. As distorções causadas por essa interação levam, frequentemente, a interpretações equivocadas sobre a realidade e as consequências dos níveis de fecundidade para o futuro da população. O efeito tempo está relacionado a mudanças na idade média da fecundidade, enquanto o efeito parturição decorre das alterações na composição da fecundidade segundo a ordem dos nascimentos ao longo do tempo e o quantum corresponde à medida pura de fecundidade, que reflete o nível da fecundidade livre de distorções.

A relevância da introdução do estudo desses componentes tem duas razões: a primeira diz respeito ao fato de que eles indicam mudanças não explícitas nas medidas tradicionais de fecundidade; e a segunda razão refere-se à importância das mínimas mudanças, principalmente em contextos de baixa fecundidade. A introdução dos conceitos e o cálculo das medidas no caso do Brasil são oportunos, em função dos níveis e tendências da fecundidade observados em períodos recentes.

O presente artigo estima e compara diferentes indicadores de fecundidade de período, mensurados em termos de número de filhos por mulher, com enfoque nos indicadores que corrigem distorções causadas na taxa de fecundidade total (TFT) observada em determinado período. Pretende-se, assim, criar e avaliar novas possibilidades de análise da fecundidade no

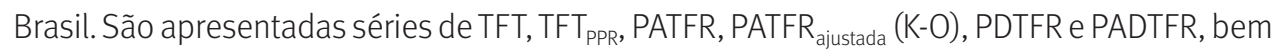
como as séries históricas dos efeitos tempo e parturição e da idade média da fecundidade. ${ }^{1}$

Para o cálculo dos indicadores, foram utilizados os bancos de dados sobre histórias de nascimentos reconstruídas a partir das edições de 1980, 1991 e 2000 do Censo Demográfico brasileiro (MIRANDA-RIBEIRO; RIOS-NETO; CARVALHO, 2009). O período de cobertura da série de cada indicador depende das limitações impostas pelas bases de dados, o que será discutido posteriormente.

\footnotetext{
${ }^{1}$ Os indicadores serão definidos ao longo do texto. No Anexo encontra-se um quadro-resumo, contendo breve descrição e definição dos indicadores calculados.
} 


\section{Efeito tempo: a translação demográfica de Ryder e o modelo de Bongaarts e Feeney (B-F)}

A primeira tentativa de mensuração do efeito tempo foi feita a partir do desenvolvimento do conceito de translação demográfica, introduzido por Ryder $(1964,1980)$ e desenvolvido posteriormente por Foster (1990), Calot (1992) e Keilman (1994, 2001). Efeito tempo é o resultado das distorções em medidas de fecundidade causadas pelas alterações na idade média da fecundidade durante determinado período.

A translação demográfica pode ser definida como uma relação entre medidas de fecundidade de período e de coorte. Seu conceito foi desenvolvido a partir da constatação de que mudanças na idade média da fecundidade de uma coorte afetam sobremaneira a fecundidade medida no período. Ryder (1964) pressupôs que a função de fecundidade pode ser expandida em uma série de Taylor separadamente para as idades e, a partir de aproximações, chegou a uma equação que relaciona a taxa de fecundidade total de coorte (TFTc) e a taxa de fecundidade total de período (TFT), na qual c é a variação linear da idade média da fecundidade observada entre as coortes.

$$
\text { TFTC }=\frac{T F T}{(1-c)}
$$

A equação mostra que, se uma coorte adiar o nascimento dos filhos durante um período, a fecundidade daquele período cairá para um valor abaixo da fecundidade da coorte. O contrário, isto é, se a coorte adiantar o nascimento dos filhos durante um período, a fecundidade do período será maior que a fecundidade da coorte.

No modelo desenvolvido por Bongaarts e Feeney (1998), o efeito tempo, embora também se refira a mudanças na idade média da fecundidade, não está relacionado à transformação de medidas de coorte em medidas de período ou vice-versa. O efeito tempo corresponde somente a medidas de período e diz respeito às distorções causadas na TFT decorrentes das variações na idade média da fecundidade ocorridas durante o período em que a TFT é mensurada. O objetivo principal do modelo de Bongaarts e Feeney (modelo B-F) é estabelecer uma medida de TFT ajustada, livre das distorções causadas pelo efeito tempo, ou seja, livre de distorções provocadas pelas mudanças na idade média da fecundidade.

O modelo B-F propõe o cálculo de uma nova TFT, ajustada às mudanças na idade média da fecundidade ( TFT $_{\text {ajustada }}$ ), representando o valor que seria alcançado pela TFT, não fossem as mudanças na idade média da fecundidade. Esse suposto valor de TFT é o que os autores definem como quantum. Embora a interpretação dos resultados seja totalmente diferente, o modelo B-F chega a resultados muito próximos dos obtidos pela equação de Ryder (1956), para pequenas mudanças na idade média da fecundidade de período (KEILMAN, 2001).

No desenvolvimento do modelo, os autores partiram da constatação de que mudanças que acontecem na fecundidade em determinado período podem ocorrer em qualquer idade ou ordem de nascimento e como consequência de alterações do tempo ou do quantum. Assim, o modelo trabalha os dados desagregados segundo a ordem de nascimento, $i$, e 
utiliza uma adaptação da equação (1), desenvolvida por Ryder, para chegar à equação que calcula a TFT ajustada.

$$
T F T_{i, \text { ajustada }}=\frac{T F T_{i, \text { observada }}}{\left(1-r_{i}\right)}
$$

na qual TFT $T_{i, \text { observada }}$ é a taxa de fecundidade total observada para a ordem de nascimento $i$, e $r_{i}$ corresponde à variação anual da idade média da fecundidade para a ordem de nascimento $i$ (medida em anos).

A TFT $T_{i, \text { observada }}$ é calculada como a soma das $\operatorname{TEF}_{\mathrm{i}, \text { observada, }}$ conforme indica a equação (3):

$$
\operatorname{TFT}_{i, \text { observada }}=\sum T E F_{i, \text { observada }}
$$

A TFT $_{\text {ajustada }}$ é calculada como a soma das TFT $_{\mathrm{i}, \text { ajustada }}$, para cada ordem $i$ de nascimento, conforme mostra a equação (4):

$$
T F T_{\text {ajustada }}=\sum T F T_{i, \text { ajustada }}
$$

Os dados para a aplicação do modelo B-F podem ser retirados de pesquisas domiciliares transversais, que permitam o cálculo da taxa de fecundidade total segundo a ordem de nascimento. 0 cálculo da variação anual da idade média da fecundidade, $r_{i}$, pode ser feito a partir da utilização de duas edições das pesquisas, dividindo-se a variação total pelo tempo decorrido entre as edições. A facilidade de aplicação do modelo levou a uma série de estudos, em diversos países e regiões. No entanto, a validade da TFT ajustada, enquanto uma medida de quantum pura, livre do efeito tempo, foi bastante questionada.

As duas principais críticas ao modelo B-F referem-se ao fato de os autores desconsiderarem os diferenciais de coorte na mudança da idade média da fecundidade e usarem medidas inadequadas na aplicação do modelo (VAN IMHOFF; KEILMAN, 2000). A primeira crítica diz respeito ao valor de $r_{i}$ utilizado, que pressupõe que a mudança anual na idade média da fecundidade para determinada ordem de nascimento é igual para todos os grupos etários. Isso implica que todas as mulheres, de diferentes idades e coortes, que tiveram um filho de determinada ordem durante um ano adiantaram ou adiaram este filho na mesma quantidade de tempo, ou seja, que a função de fecundidade foi constante durante o período. Van Imhoff e Keilman (2000) e Kohler e Philipov (2001) mostram empiricamente que essa suposição de constância é violada.

A segunda crítica diz respeito ao fato de o modelo utilizar taxas de fecundidade específicas por idade (TEF), cujo denominador contém todas as mulheres de determinada idade ou faixa etária, independente do número de filhos tidos. Assim, as taxas de fecundidade empregadas por B-F não são medidas de exposição ou risco, mas simplesmente frequências e, quando frequências de período são somadas para todas as idades, o resultado não pode ser interpretado como um indicador de quantum apropriado (VAN IMHOFF; KEILMAN, 2000). 


\section{Modelo de Köhler e Ortega (K-0)}

O desenvolvimento do modelo Köhler e Ortega (ORTEGA; KÖHLER, 2002) foi motivado pelas críticas ao modelo B-F e busca corrigir as falhas. Em relação às medidas, Köhler e Ortega utilizam funções de intensidade, que são taxas de fecundidade específicas por idade que empregam, no denominador, apenas as mulheres em risco de ter um filho de determinada ordem de nascimento. No que diz respeito à variação anual da idade média da fecundidade, os autores introduzem o conceito de variância (KÖHLER; PHILIPOV, 2001) e o seu cálculo passa a ser função não apenas da ordem de nascimento, como no modelo B-F, mas também da idade da mulher. Além disso, para encontrar a medida pura de quantum, o modelo proposto por Köhler e Ortega mensura o efeito da mudança na composição por parturição da fecundidade.

Desse modo, a fecundidade de período é dissociada em três componentes: efeito tempo, decorrente das mudanças na idade média da fecundidade efeito parturição, decorrente das mudanças na composição por parturição da fecundidade; e quantum, a medida pura de fecundidade, livre de distorções dos efeitos tempo e parturição. Essa medida de quantum puro pode ser interpretada como um valor hipotético de TFT que seria observado no mesmo período, não fossem as mudanças na idade média da fecundidade e as mudanças na composição por parturição da fecundidade. O modelo mensura os três componentes, o que abre caminhos para uma análise diferenciada das mudanças ocorridas na fecundidade ao longo do tempo e possibilita a inferência sobre perspectivas futuras, com base em informações fundamentais e não explícitas nas medidas tradicionais.

A mensuração da fecundidade segundo a ordem de nascimento, $i$, e idade da mulher, $a$, pode relacionar-se ao total de mulheres de idade $a$ ou ao total de mulheres de idade $a$, em risco de ter um filho ordem $i$. No primeiro caso, a medida representa as taxas específicas de fecundidade tradicionais, que utilizam, no denominador, o número total de mulheres de determinada idade, independente da sua parturição no início do período. Essas taxas, também denominadas incidências, não se configuram medidas de risco e a sua soma, para as diversas ordens, fornece a taxa de fecundidade total (RALLU; TOULEMON, 1994). No segundo caso, as taxas são denominadas intensidades, representando o risco de a mulher ter um filho de determinada ordem, e empregam, no denominador, as mulheres de idade $a$ que estão em risco de ter um filho de ordem $i$, ou seja, mulheres com parturição $i-1$ no início do período. As funções de intensidade são calculadas conforme a equação (5):

$$
m_{i}(a)=\frac{B_{i}(a)}{E_{i}(a)}
$$

na qual $B_{i}(a)$ corresponde aos nascimentos de filhos de ordem $i$, de mulheres de idade $a$ e $E_{i}(a)$ representa o número de mulheres de idade $a$ em risco de ter um nascimento de ordem $i$. As funções de incidência são calculadas conforme a equação (6):

$$
f_{i}(a)=\frac{B_{i}(a)}{E(a)}
$$


na qual $B_{i}(a)$ corresponde aos nascimentos de mulheres de idade $a$ e parturição $i$ e $E(a)$ refere-se ao número de mulheres de idade $a$, independente da sua parturição no início do período.

O cálculo das incidências é necessário para a determinação da TFT que, ao final do processo, a partir de uma relação com a medida de quantum pura, fornecerá a dimensão do efeito tempo. As taxas de fecundidade total, $\mathrm{TFT}_{\mathrm{i}}$ e TFT, são calculadas segundo as equações (7) e (8):

$$
\begin{aligned}
& \operatorname{TFT}_{i}=\sum_{a} f_{i}(a) \\
& T F T=\sum_{i} T F T_{i}=\sum_{a} f(a)
\end{aligned}
$$

As funções ajustadas de intensidade, $m_{i}^{\prime}(a)$, e incidência, $f_{i}^{\prime}(a)$ - livres do efeito tempo são calculadas, respectivamente, a partir das equações (9) e (10), que são semelhantes às desenvolvidas por Bongaarts e Feeney (1998) e Ryder (1956):

$$
\begin{aligned}
& m_{i}^{\prime}(a)=\frac{m_{i}(a)}{1-r_{i}(a)} \\
& f_{i}^{\prime}(a)=\frac{f_{i}(a)}{1-r_{i}(a)}
\end{aligned}
$$

A diferença entre as equações (9) e (10) e a equação (2) é que a variação da idade média da fecundidade, $r_{i}(a)$, é função não apenas a ordem de nascimento, $i$, mas também da idade da mulher, $a$. Dessa forma, o modelo K-O corrige uma das falhas do modelo B-F, ao considerar que a variação na idade média da fecundidade, para determinada ordem de nascimento, pode ser diferente para mulheres de idades diferentes.

A determinação da função $r_{i}(a)$ foi desenvolvida por Köhler e Philipov (2001), a partir da observação de que, durante o declínio próximo da fecundidade ocorrido em alguns países europeus, o aumento da idade média da fecundidade havia sido frequentemente acompanhado por mudanças na forma da função de fecundidade, representando uma violação da fórmula do modelo B-F, que pressupõe uma variação constante segundo a ordem de nascimento, ou seja, a não interação coorte-período.

De acordo com Köhler e Philipov (2001), o efeito tempo pode variar com a idade, sendo que a variância da função de fecundidade pode aumentar ou diminuir ao longo do tempo. Considerando esses aspectos, os autores desenvolveram um processo iterativo que calcula alguns parâmetros, por idade e ordem de nascimento, a partir de uma série histórica de funções de intensidade. Esses parâmetros, por sua vez, são utilizados para o cálculo do $r_{i}(a)$ - a variação anual da idade média da fecundidade segundo a ordem de nascimento e a idade da mulher, conforme a equação (11):

$$
r_{i}(a)=\gamma_{i}+\delta_{i}\left(a-\bar{a}_{i}\right)
$$


na qual $\gamma_{i}$ e $\delta_{i}$ são os parâmetros gama e delta, calculados pelo processo iterativo. ${ }^{2}$ Gama representa a mudança na idade média da fecundidade, ao passo que delta é a mudança proporcional no desvio padrão da idade média. O parâmetro $\bar{a}_{j}$, também um dos produtos do processo iterativo, é a idade média da função ajustada de fecundidade.

Uma vez determinados os valores de $r_{i}(a)$, podem ser calculadas as funções de intensidade e incidência ajustadas, indicadas nas equações (9) e (10). Substituindo as incidências por aquelas ajustadas nas equações (7) e (8), calculam-se as taxas de fecundidade total ajustadas, por ordem de nascimento e para todas as ordens de nascimento, TFT,' e TFT'.

As medidas ajustadas são livres do efeito tempo. Uma vez calculadas, a atenção se volta para a determinação de uma medida de período que seja livre do efeito das mudanças na composição da fecundidade segundo a parturição. A taxa de fecundidade observada em determinado período é uma medida que, conceitualmente, refere-se à fecundidade de uma coorte hipotética, formada por mulheres de diversas coortes reais. Por esse aspecto, a medida carrega, na sua essência, a experiência passada dessas diversas coortes reais. Se a composição por parturição de coortes reais sucessivas for diferente, ocorrerá que, na composição de uma coorte hipotética em determinado período, o número de mulheres ao final de um grupo etário com determinada parturição será diferente do número de mulheres no início do grupo etário seguinte com a mesma parturição. Isso mostra que a TFT é uma medida não controlada por parturição.

A taxa de fecundidade total de uma coorte real, por outro lado, é uma medida livre dos efeitos da composição da fecundidade segundo a parturição. Assim, a solução seria encontrar uma medida de período em que a coorte sintética assumisse o comportamento de uma coorte real. Isso é possível por meio de uma tábua de fecundidade controlada por idade e parturição, que representa o comportamento reprodutivo de uma coorte hipotética, sujeita a taxas observadas em um período, mas, ao mesmo tempo, simula o comportamento de uma coorte real, ao acompanhar um grupo de mulheres desde a entrada até a saída do período reprodutivo, passando pelas diversas parturições.

A medida básica para utilização de uma tábua de fecundidade é a probabilidade de mulheres de parturição $i$ - 1 à idade $a$ terem um nascimento de ordem $i$, entre as idades exatas $a$ e $a+1$. Para o cálculo das funções de probabilidade, Ortega e Köhler (2002) sugerem o uso das funções de intensidade, porque a progressão de uma parturição a outra é um evento não renovável. Assim, seria incorreto empregar as funções de incidências no cálculo das probabilidades. A transformação das taxas em probabilidades pode ser feita conforme a equação (12). A utilização de funções de intensidade ajustadas resulta em probabilidades ajustadas.

$q_{i}(a)=1-\exp \left[-m_{i}(a)\right]$

\footnotetext{
${ }^{2}$ Os programas para aplicação do processo iterativo estão disponiveis em: 〈http://www.ssc.upenn.edu/ hpkohler/dataand-programs/ko-ppr/ko-ppr-programs.html\#x1-30002〉.
} 
A partir das probabilidades da equação (12), são calculadas outras funções da tábua de fecundidade. A equação (13) mostra como é calculado o número de nascimentos de ordem $i$, de mulheres de idade $a, b_{i}(a)$ :

$$
b_{i}(a)=D_{i}(a) q_{i}(a)
$$

na qual $D_{i}(a)$ é o número de mulheres de idade $a$ e parturição $j$. Um processo iterativo que utiliza as equações (13) e (14) calcula o número de mulheres e de nascimentos.

$$
D_{i}(a+1)=D_{i}(a)-b_{i}(a)+b_{i-1}(a)
$$

Para o último grupo de parturição, I, que inclui as ordens de nascimento I e as maiores que I, o número de nascimentos e de mulheres é calculado segundo as fórmulas das equações (15) e (16).

$$
\begin{aligned}
& b_{I}(a)=D_{I}(a) f_{I}(a) \\
& D_{I}(a+1)=D_{I}(a)-b_{I-1}(a)
\end{aligned}
$$

O número de mulheres na condição inicial da tábua de fecundidade (raiz), de idade $\alpha$ e parturição $i=0$, é igual a N. À exata idade $\alpha$ e parturição $i>0$, o número de mulheres é nulo. 0 número médio de nascimentos de mulheres da coorte sintética é definido pela equação (17):

$$
b_{i 1, i 2}\left(a_{0}, a_{1}\right)=\sum_{a=a}^{a 1} \sum_{0 i=i 1}^{i 2} b_{i}(a)
$$

A medida sintética da tábua de fecundidade é obtida pela razão entre a soma de todos os nascimentos da coorte sintética e a raiz da tábua de fecundidade, de acordo com a equação (18). Essa medida é também denominada taxa de fecundidade total específica por idade e parturição, PATFR (parity and age specific total fertility rate).

$$
\operatorname{PATFR}=b_{\mathrm{O}, I}(\alpha, \omega) / N=b_{\mathrm{O}, I}(\alpha) / N
$$

A PATFR, quando construída a partir das intensidades ajustadas pelo efeito tempo, é livre dos efeitos tempo e parturição e denominada PATFR ${ }_{\text {ajustada. }}$. Esta medida é a que Ortega e Köhler (2002) chamam de medida pura ou quantum puro.

Uma vez calculadas as medidas livres dos efeitos tempo e parturição, é possivel mensurar os efeitos. Ortega e Köhler (2002) propõem a mensuração destes efeitos de forma similar àquela do efeito tempo proposta por Bongaarts e Feeney (1998), que chamam de efeito tempo a variação anual da idade média da fecundidade, $r_{i}$. Utilizando uma variação da equação (2), os autores chegam à equação (19), na qual $r$ é o efeito tempo.

$$
r_{i}=1-\frac{T F T_{\text {observada }}}{T F T_{\text {ajustada }}}
$$

Um valor positivo de $r$ indica uma razão entre a TFT $T_{\text {observada }}$ e a $T_{\text {ajustada }}$ menor que a

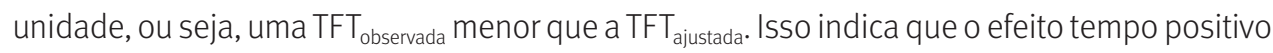




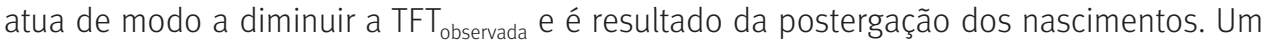
valor negativo de $r$ - efeito tempo negativo - indica o contrário, ou seja, um adiantamento dos nascimentos.

Analogamente, calcula-se o efeito parturição, $d$, utilizando-se as duas medidas livres do efeito tempo, TFT ajustada e PATFR ajustada. $_{\text {. }}$ sinal invertido da equação (20) faz com que o efeito parturição seja positivo quando favorece o aumento da fecundidade observada, o oposto do efeito tempo.

$$
d=\frac{T F T_{\text {ajustada }}}{P A T F R_{\text {ajustada }}}-1
$$

\section{Medidas de fecundidade de período baseadas em probabilidades: PDTFR, PADTFR, PPR e TFT $_{\text {PPR }}$}

Ni Bhrolcháin (1992) sugere que algumas medidas baseadas em probabilidade, como as PDTFR, PADTFR e PPR, devam ser incluídas na agenda dos indicadores de fecundidade. As probabilidades utilizadas para o cálculo das medidas são aproximações obtidas a partir da transformação das taxas observadas no período. Essas medidas, no entanto, não são muito difundidas, pois os dados necessários ao seu cálculo não estão disponíveis para um grande número de localidades e nem para um longo período de tempo. O banco de dados sobre histórias de nascimentos tornou possível o cálculo dessas medidas para o caso brasileiro. Entretanto, o fato de cada censo voltar 15 anos no tempo pode limitar a análise desses indicadores porque são censuradas as informações sobre nascimentos que ocorreram fora desse período. Parte dos nascimentos ocorridos fora do período é anterior àqueles que ocorreram dentro do período e, nesses casos, o intervalo entre nascimentos é uma variável indefinida.

\section{Taxa de fecundidade total controlada por duração e parturição - PDTFR}

As equações (12) a (18) mostradas anteriormente descrevem o cálculo da PATFR, a partir de funções de uma tábua de fecundidade, sendo que as probabilidades utilizadas são derivadas das funções de intensidade, que representam o risco de uma mulher de idade $a$ ter um filho de ordem $i$, em determinado ano. Já para o cálculo da PDTFR, busca-se a probabilidade de uma mulher ter um filho de ordem $i$, em função da duração, $d$, desde o evento anterior. O evento anterior é o nascimento do filho de ordem anterior, para os nascimentos de segunda ordem ou ordens superiores, ou a entrada no período reprodutivo, no caso dos nascimentos de primeira ordem. Em alguns casos, considera-se como evento anterior ter completado 14 anos, no caso de nascimentos de primeira ordem, porque se garante a não ocorrência de nascimentos no ano zero. Dessa forma, tem-se um indicador de período controlado apenas por duração e parturição e não por idade, como no caso da PATFR.

A PDTFR, indicador controlado por duração e parturição, é livre das mudanças do tempo da fecundidade e das alterações da composição da fecundidade por parturição, mas não 
leva em conta os diferenciais de coorte, visto que considera o comportamento reprodutivo independente da idade da mulher.

A equação (21) é uma reprodução da equação (12), mas coloca a probabilidade de a mulher ter um filho de ordem $i$, em função da duração desde o evento anterior. 0 ano, $t$, é um parâmetro implícito nos cálculos.

$$
q_{i}(d)=1-\exp \left[-m_{i}(d)\right]
$$

A função $m_{i}(d)$ é definida pela equação $(22)$, na qual $B_{i}(d)$ corresponde aos nascimentos dos filhos de ordem $i$, daquelas mulheres que tiveram o evento anterior no momento $j$ - $d$. 0 evento anterior é o nascimento do filho de ordem $i-1$ (ou a entrada no período reprodutivo, para nascimentos de primeira ordem). O denominador, $E_{i}(d)$, representa o número de mulheres em risco de apresentar o evento $B_{i}(d)$, ou seja, são mulheres com parturição $i-1$ e que tiveram o filho de ordem $i$ no ano $j$ - $d$.

$$
m_{i}(d)=\frac{B_{i}(d)}{E_{i}(d)}
$$

Definidas as funções e as probabilidades, o procedimento para o cálculo da PDTFR é o mesmo descrito no cálculo da PATFR (equações 12 a 21), no qual há a progressão entre as parturições e durações.

\section{Taxa de fecundidade total controlada por idade, parturição e duração - PADTFR}

O cálculo da taxa de fecundidade total controlada por idade, parturição e duração PADTFR - é mais complexo que o dos demais indicadores derivados de tábuas de fecundidade, porque as taxas e probabilidades utilizadas incluem uma terceira dimensão. Para a aplicação das probabilidades em uma tábua de fecundidade bidimensional, há a necessidade de se diminuir a dimensionalidade das probabilidades. Pode-se reduzir a dimensionalidade de qualquer uma das variáveis e a opção feita neste trabalho é a de tornar as probabilidades funções da idade da mulher e da ordem de nascimento, conforme sugeriram Rallu e Toulemon (1994).

O objetivo primeiro é determinar as $q(a, i, d)$, que indicam a probabilidade de uma mulher de idade $a$ ter um filho de ordem $i$, dado que a duração desde o evento anterior é $d$. A equação (23), que expressa a probabilidade em função das taxas, é semelhante às equações (12) e (21). Novamente, o ano $j$ é um parâmetro implícito nos cálculos. A função $m_{i}(a, d)$ é definida na equação (24), na qual $B_{i}(a, d)$ corresponde aos nascimentos de ordem $i$, de mulheres de idade $a$ cuja duração desde o evento anterior é $d$; e $E_{i}(a, d)$ refere-se ao número de mulheres de parturição $i-1$, com idade $a$ e cujo nascimento de ordem $i-1$ ocorreu $d$ anos antes do ano j. O parâmetro $a$ é a idade declarada no censo.

$$
\begin{aligned}
& q_{i}(a, d)=1-\exp \left[-m_{i}(a, d)\right] \\
& m_{i}(a, d)=\frac{B_{i}(a, d)}{E_{i}(a, d)}
\end{aligned}
$$


Determinadas as probabilidades $q_{i}(a, d)$, obtêm-se as probabilidades $q_{i}(a)$, a partir da equação (25), de Rallu e Toulemon (1994), na qual $N_{i}(a, d)$ é o número de mulheres de idade $a$, parturição $i$ e duração $d$ desde o evento anterior.

$$
q_{i}(a)=\frac{\sum_{d} N i(a, d) \cdot q_{i}(a, d)}{\sum_{d} N i(a, d)}
$$

Em seguida, as novas probabilidades são utilizadas para o cálculo das funções da tábua de fecundidade, como na PATFR. A diferença é que, neste caso, a medida síntese, PADTFR, não sofre influência das variações na duração do intervalo entre filhos. Por ser livre também dos efeitos causados nas mudanças da composição da fecundidade por parturição, essa medida é denominada por Rallu e Toulemon (1994) de medida de fecundidade completa, pois independe dos efeitos do passado. Conceitualmente, essa é a mesma proposta da medida pura do modelo K-O (PATFR ajustada $_{2}$.

\section{Razão de progressão de parturição (PPR) e taxa de fecundidade total derivada das $P P R$ (TFT $\left.T_{P P R}\right)$}

O procedimento para calcular a PPR de período foi proposto por Louis Henry, nos anos 1950, e redescoberto por Feeney e Yu (1987) e Ni Bhrolcháin (1987). Para a sua aplicação, são necessários dados de pesquisas em que haja a possibilidade de identificar o momento do nascimento dos filhos das mulheres enumeradas. Uma vez disponíveis esses dados, há duas possibilidades de calcular PPR de período, conhecidas como "coorte verdadeira de parturição"3 e "coorte sintética de parturição"4 (HINDE, 1998). A partir das PPR, é possível calcular a taxa de fecundidade total de período - a TFT $T_{\text {PPR }}$ - que, diversamente da TFT convencional, não é função da idade da mulher.

A ideia por trás do procedimento conhecido como "coorte verdadeira de parturição" é a de fixar um determinado ano $j_{\text {ind }}$ (ano índice) e identificar todas as mulheres que tiveram filhos de ordem $i$ naquele ano. Ao acompanhar essas mulheres por alguns anos, é possivel identificar se elas tiveram e em que ano subsequente tiveram o filho de ordem $i+1$. No procedimento conhecido como "coorte sintética de parturição", a ideia é fixar o ano em que as mulheres tiveram o filho de ordem $i+1$ e buscar, retrospectivamente, o ano em que tiveram o filho de ordem $i$. Duas desvantagens no cálculo das PPR a partir do procedimento da coorte verdadeira são: a maior chance de censura dos dados para os anos mais próximos do censo, visto que o ano do nascimento do filho de ordem $i+1$ não é fixo; e a ocorrência, em alguns anos antes do censo, de grande parte dos nascimentos incluídos nos cálculos, o que torna os resultados um pouco desatualizados. Esses problemas ocorrem em menor grau no procedimento da coorte sintética, motivo pelo qual será aplicado neste artigo.

\footnotetext{
3 Do termo em inglês true parity cohorts.

4 Do termo em inglês synthetic parity cohorts.
} 
O primeiro passo no procedimento é o cálculo das proporções $q_{x}{ }^{* \star}$, que serão utilizadas para o cálculo das PPR. 0 ano $j$ é um parâmetro implícito no cálculo e $x$ indica o tempo, medido em anos. Na equação (26), o numerador $E_{i(j-x), i+1(j)}$ representa o número de mulheres que tiveram o filho de ordem $i$ no ano $j$ - $x$ e o filho de ordem $i+1$ no ano $j$. No numerador, $E_{i(j-x)}$ indica o número de mulheres que tiveram o filho de ordem $i$ no ano $j$ - $x$ e $E_{i(j-x), i+1[j-x, t)}$ indica o número de mulheres que tiveram o filho de ordem $i$ no ano $j$ - $x$ e tiveram o filho de ordem $i+1$ antes do ano $j$ (esse ano pode ser, inclusive, o ano $j-x$ ).

$$
q_{x}^{* *}=\frac{E_{i(j-x), i+1(j)}}{E_{i(j-x)}-E_{i(j-x), i+1[j-x, j)}}
$$

O valor do parâmetro $x$ pode variar desde zero (quando os filhos de ordem $i$ e $i+1$ nasceram no mesmo ano) até um limite considerado apropriado, em geral não maior que dez (HINDE, 1998), mas que depende da disponibilidade dos dados. As probabilidades de progressão de parturição (PPR) de período do nascimento de ordem $i$ para o nascimento de ordem $i+1$, identificadas por $a_{i}$, podem ser calculadas a partir da equação (27). Calculadas as $a_{i}$ para as diversas ordens de nascimento, calcula-se a TFT PPR (equação 28).

$$
\begin{aligned}
& a_{i}=1-\left(1-q_{0}^{* \star}\right)\left(1-q_{1}^{* \star}\right)\left(1-q_{2}^{* \star}\right) \ldots\left(1-q_{\text {máx }}^{* \star}\right) \\
& T_{F T} T_{P P R}=a_{0}+a_{0} a_{1}+a_{0} a_{1} a_{2}+\ldots+a_{0} a_{1} a_{2} \ldots a_{\text {máx }}
\end{aligned}
$$

\section{Limitações impostas pelas bases de dados ao cálculo das medidas}

Os indicadores descritos podem ser afetados por três tipos de limitações impostas pelas bases de dados, que tendem, em graus diferenciados, a subestimar as medidas apresentadas. A primeira limitação afeta as medidas baseadas em duração desde o evento anterior e relaciona-se ao fato de as bases de dados cobrirem um período retrospectivo de 15 anos para cada censo. Isso significa que, para os anos de realização dos censos, o tempo para observação do evento anterior é de 14 anos. À medida que se afasta dos anos de realização dos censos, esse tempo retrospectivo diminui. Para garantir que o tempo de observação não seja inferior a dez anos, ${ }^{5}$ as séries históricas das medidas baseadas em duração iniciam-se no quarto ano anterior ao da realização de cada censo. As séries mais curtas amenizam o problema da duração, mas não resolvem o problema da censura das informações de mulheres mais velhas, cuja parte do período reprodutivo não está coberto nas histórias de nascimentos reconstruídas. Dessa forma, não se tem a informação sobre os filhos nascidos fora do período de cobertura. Isso não seria problema se parte desses filhos nascidos fora do período de cobertura não representasse o evento anterior ao nascimento

\footnotetext{
5 De acordo com Rallu e Toulemon (1994), não existe uma regra fixa que determine o valor da duração máxima entre dois nascimentos a ser considerado. No caso do Brasil, o aspecto determinante na definição deste valor foi a imposição causada pelo tamanho da série retrospectiva. Os eventos anteriores cuja duração exceda o período de dez anos são desconsiderados na análise.
} 
dos filhos nascidos dentro do período de cobertura. A implicação da censura é um alto índice de indeterminação de intervalos de nascimentos para mulheres mais velhas. A solução, neste caso, foi calcular a série de indicadores considerando a fecundidade acumulada até os 30 anos de idade, porque grande parte do período reprodutivo dessas mulheres está coberta pelas histórias de nascimentos.

A segunda limitação que pode afetar o cálculo dos indicadores está relacionada à qualidade das informações nos anos mais afastados dos censos. Nos bancos de dados sobre histórias de nascimentos reconstruídas a partir dos censos demográficos, a tendência é que, à medida que se afasta do ano de realização do censo, a qualidade dos dados diminua. Isso ocorre para os dados agregados e se intensifica conforme as informações são desagregadas. A análise das intensidades e a comparação nos anos em que as séries de dois censos consecutivos se sobrepõem evidenciaram essa questão. Tal limitação afeta tanto as medidas derivadas do modelo K-O quanto aquelas baseadas em duração. No primeiro caso, a limitação afeta o cálculo dos parâmetros delta e gama, que determinam o valor de $r_{i}(a)$, porque o processo iterativo que determina delta e gama utiliza dados da série completa de intensidades para determinar os parâmetros de um único ano. Se os dados dos anos mais afastados estão distorcidos, os parâmetros e, consequentemente, o valor de $r_{i}(a)$ sofrerão algum tipo de distorção. Em relação às medidas baseadas em duração, a qualidade das informações nos anos mais afastados dos censos afeta as medidas no caso de nascimentos consecutivos com duração mais longa. Neste artigo, optou-se pela utilização da série parcial de intensidades (dez anos).

A terceira limitação está relacionada à possível omissão de crianças nas primeiras idades e a erros de declaração da idade. Nos modelos utilizados, que combinam a idade da criança e a ordem de nascimento, esses problemas tendem a distorcer ainda mais os dados, principalmente nos anos mais próximos aos censos.

\section{Tempo e quantum da fecundidade: evidências empíricas}

Os resultados apresentados buscam uma interpretação da transição da fecundidade no Brasil a partir de aspectos não evidentes na TFT, medida comumente utilizada na análise da fecundidade brasileira. Pelo fato de os dados considerarem o Brasil na sua totalidade, os resultados estão carregados de toda a heterogeneidade do comportamento reprodutivo das mulheres brasileiras. Tendo isso em mente, pretende-se, com os resultados, uma primeira aproximação, para que estudos futuros abordem aspectos mais específicos, como grupos de mulheres mais homogêneos.

Efeito tempo, quantum e efeito parturição: resultados da aplicação do modelo $\mathrm{K}$-O aos dados brasileiros

Os resultados da aplicação do modelo K-O aos dados brasileiros mostram que, ao contrário do que se verifica na Europa, a queda da fecundidade no Brasil ocorreu sob a 
atuação de um efeito tempo negativo, indicando que a taxa de fecundidade total observada foi inflada pelo adiantamento no nascimento dos filhos. O efeito parturição no Brasil foi significativo e atuou no mesmo sentido do efeito tempo, o de aumentar a TFT medida durante todo o período. A análise da atuação conjunta dos dois efeitos pode ser feita a partir dos valores encontrados para o quantum puro, a PATFR ajustada, que podem ser interpretados como os valores que a TFT alcançaria se não fossem as atuações dos efeitos tempo e parturição.

As curvas dos efeitos tempo e parturição dos três Censos Demográficos não se sobrepõem, como se esperaria em uma situação ideal. Uma explicação pode estar relacionada à diferença entre as funções de intensidade derivadas dos diversos censos. Se as funções de intensidade para um mesmo ano diferem significativamente de um censo para outro (no período em que há sobreposição da cobertura da história de nascimentos para dois censos consecutivos), a geração de parâmetros do modelo K-O e respectivos cálculos de medidas ajustadas para os efeitos tempo e parturição são distorcidos por essas diferenças. Assim, quanto maior a diferença entre as funções de um mesmo ano, derivadas de censos diferentes, maiores as diferenças entre os parâmetros e, consequentemente, entre as curvas. A diferença entre as funções para um mesmo ano relaciona-se à distorção das medidas em anos mais afastados do ano de realização do censo e diz respeito ao fato de que, para cada censo, foram utilizadas as funções geradas pelo próprio censo.

A série histórica anual do efeito tempo no Brasil é apresentada no Gráfico 1, que mostra a série de efeito tempo para o período 1970-2000, obtida pela aplicação do modelo para as séries parciais (dez anos) de cada censo, considerando-se todas as parturições (efeito tempo total). Em função das flutuações mostradas nas curvas e das distorções comentadas anteriormente, não é prudente se falar em termos da magnitude do efeito tempo para o Brasil com os resultados apresentados. No entanto, observa-se uma tendência que pode ser uma boa indicação do que ocorreu no país nas últimas décadas e do que pode acontecer no futuro próximo.

De acordo com o Gráfico 1, o efeito tempo negativo no Brasil contribuiu para um aumento da TFT observada durante praticamente todo o período. Efeito tempo negativo indica que houve queda da idade média da fecundidade. Essa redução no Brasil, nas últimas décadas, mostrada no Gráfico 1, ${ }^{6}$ não é novidade e já foi evidenciada em grande parte dos estudos sobre fecundidade no país. A novidade fica por conta da interpretação e da projeção do efeito tempo. Observa-se, ao final do período, uma tendência de efeito tempo próximo de zero, o que indicaria certa estabilização na queda da idade média da fecundidade, considerando o total do país. A tendência de estabilização indicada pelo efeito tempo é corroborada pela curva da idade média da fecundidade.

\footnotetext{
${ }^{6}$ Os valores da idade média da fecundidade, no período 1970-2000, foram retirados de Miranda-Ribeiro (2007) e obtidos pela aplicação do Método dos Filhos Próprios aos Censos Demográficos de 1980, 1991 e 2000.
} 


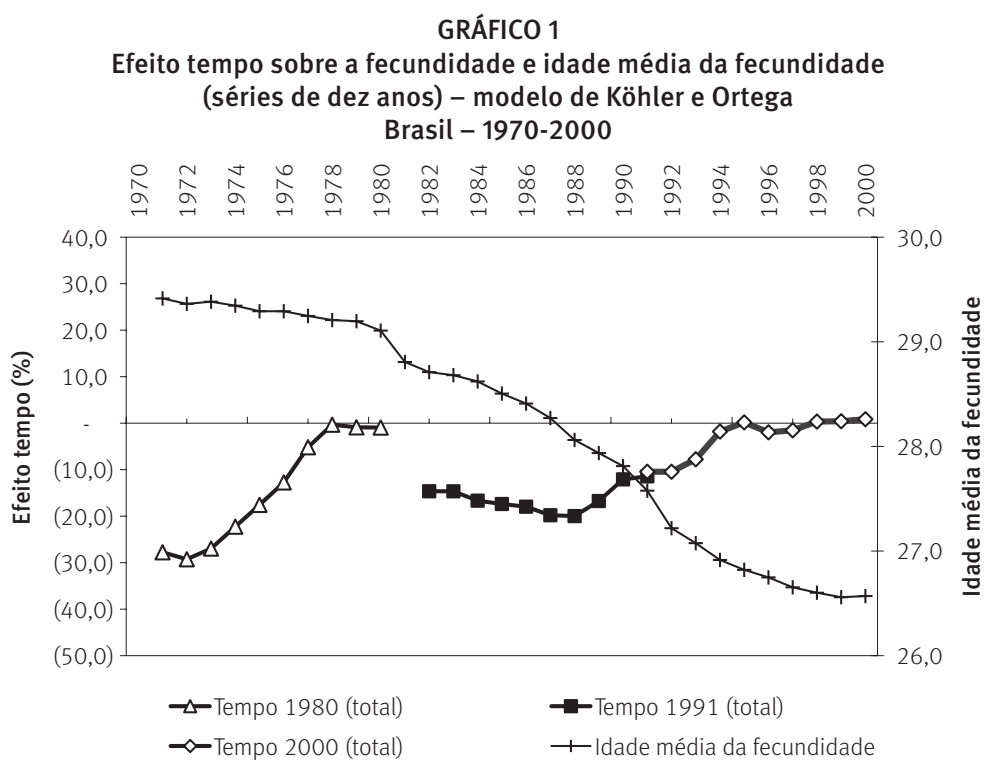

Fonte: IBGE. Censos Demográficos de 1980, 1991 e 2000.

O Gráfico 2 mostra a série de efeito da composição por parturição, ou efeito parturição, para a série parcial (dez anos) de intensidades. Em termos de tendência, observa-se que o efeito parturição no Brasil foi positivo durante praticamente todo o período de análise. Isso implica que o efeito parturição atuou no mesmo sentido do efeito tempo, o de inflar a fecundidade observada durante o período. Quando o efeito parturição provoca crescimento da fecundidade observada, isso indica que a composição por parturição está sendo modificada no sentido de aumentar a participação relativa das parturições que têm taxas mais altas ou, olhando no sentido inverso, de diminuir a participação relativa das parturições que têm taxas mais baixas. 0 efeito parturição positivo, portanto, implica um aumento da participação relativa das ordens de nascimento inferiores, em detrimento da queda da participação relativa das ordens superiores. Os resultados do efeito parturição são consistentes com o fato de que a queda da fecundidade, no Brasil, ocorreu em grande parte pela redução da fecundidade nas ordens superiores de nascimento. Ao contrário do efeito tempo, a curva do efeito parturição em 1991 não teve aderência à curva de 2000.

O Gráfico 3 mostra a série histórica da idade média da fecundidade da medida controlada por idade e parturição, para primeira e segunda ordens de nascimento. Essa medida é, portanto, livre dos efeitos da composição da fecundidade segundo a parturição e pode ser interpretada como o valor que a idade média da fecundidade assumiria se não houvesse mudanças na composição da fecundidade segundo a parturição. Na prática, ela mostra as mudanças na idade média da fecundidade que se devem apenas à atuação do efeito tempo. É possível observar que ao final da série, para as duas ordens de nascimento, a idade média da fecundidade apresenta tendência de elevação, sendo mais forte para a segunda ordem de nascimento. 
GRÁFICO 2

Efeito composição por parturição sobre a fecundidade (série de dez anos) - modelo de Köhler e Ortega Brasil - 1970-2000

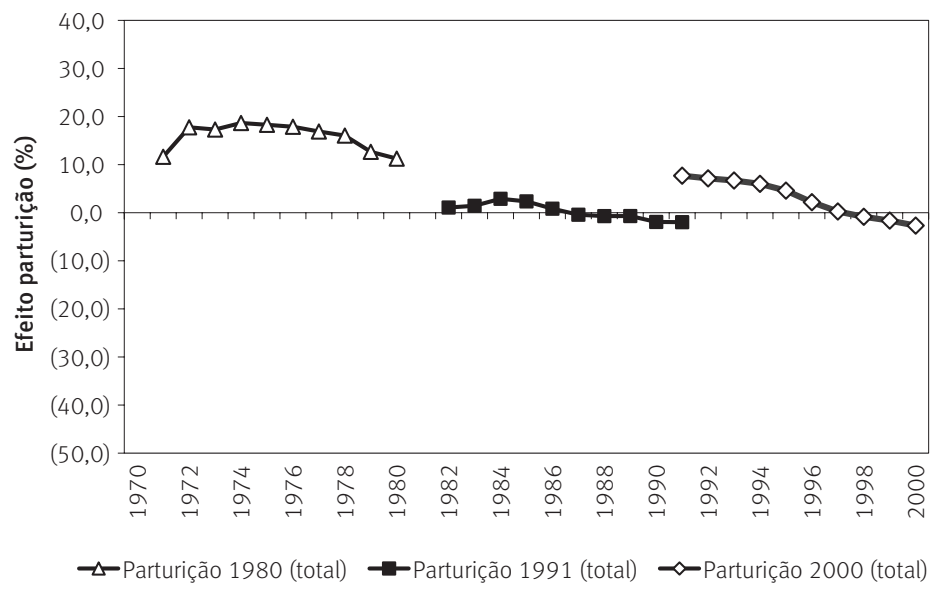

Fonte: IBGE. Censos Demográficos de 1980, 1991 e 2000.

GRÁFICO 3

Idade média da fecundidade controlada por idade e parturição - Modelo de Köhler e Ortega Brasil - 1966-2000

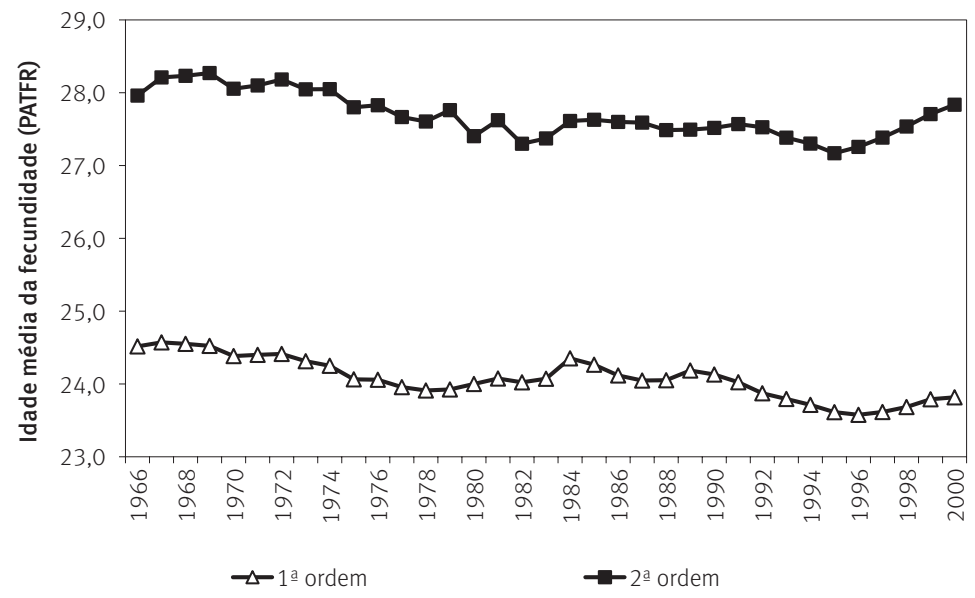

Fonte: IBGE. Censos Demográficos de 1980, 1991 e 2000.

Medida baseada na probabilidade de progressão de parturição: TFT PPR

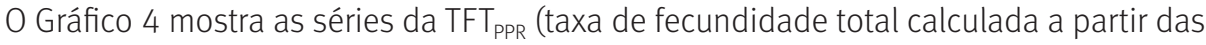
razões de progressão de parturição) e da TFT tradicional calculadas com os dados dos três Censos Demográficos. A TFT PPR (assim como a PDTFR) é uma medida não controlada por idade, calculada a partir das razões de progressão de parturição. Apesar das diferenças metodológicas, o Gráfico 4 mostra resultados consistentes, visto que a diferença entre a $\operatorname{TFT}_{\text {PPR }}$ e a TFT tradicional é pequena, principalmente na série do Censo de 1991. É provável que parte das diferenças deva-se à limitação do banco de dados - em relação ao período de 
retrocesso -, pois uma série maior implicaria um valor máximo maior para $x$, no cálculo das probabilidades, $q_{x}^{* *}$. Apesar dos resultados satisfatórios, o cálculo da TFT tradicional é mais simples e requer dados menos sofisticados. As séries curtas de TFT $T_{\text {PPR }}$ foram determinadas para que o valor de $x$ não fosse inferior a dez anos. A forma das curvas apresentadas indica a probabilidade de que as medidas estejam, por algum motivo, distorcidas nos anos mais próximos aos censos. Subenumeração de crianças menores pode ser uma das explicações. Assim, para efeito de análise, a série do Censo de 1980 cobre o período 1976-1978; a do Censo de 1991, 1987-1989; e a série 2000 abrange o período 1996-1998. As linhas pontilhadas mostram os valores dos anos mais próximos aos dos censos, omitidos das séries. As observações valem para as demais medidas.

\section{GRÁFICO 4 \\ Taxa de fecundidade total calculada a partir das razões de progressão de parturição (TFTPPR) e taxa de fecundidade total (TFT) \\ Brasil - 1976-2000}

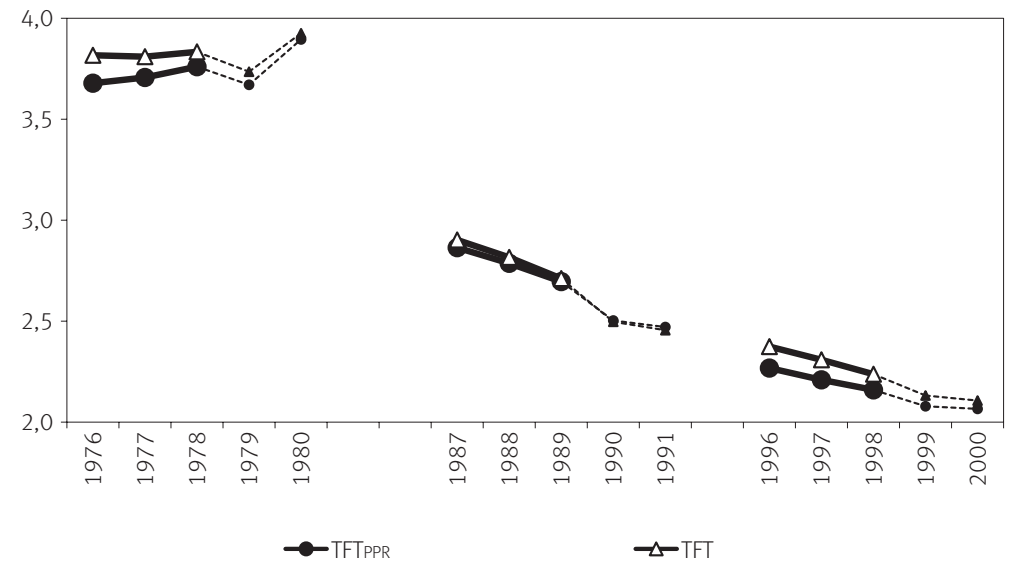

Fonte: IBGE. Censos Demográficos de 1980, 1991 e 2000

\section{Medidas baseadas em duração desde o evento anterior: PDTFR e PADTFR}

As séries históricas das medidas baseadas em duração desde o evento anterior sofrem com os dois primeiros tipos de problemas relacionados às bases de dados, descritos anteriormente, quais sejam: a censura dos dados e a qualidade das informações nos anos mais afastados dos censos. O Gráfico 5 apresenta as séries da PDTFR (taxa de fecundidade total por parturição e duração) e o Gráfico 6 traz as séries da taxa de fecundidade total controlada por idade, parturição e duração, PADTFR, comparadas com as séries de PATFR $_{\text {ajustada }}$ (modelo K-O).

A série PDTFR é a mais afetada pela censura dos dados. Por ser função da parturição e da duração, a construção da medida a partir da tábua de fecundidade funciona como se as mulheres da coorte sintética tivessem apenas dez anos para completar a sua parturição. Isso implica que parte delas não chega a ter o primeiro filho e, daquelas que o têm, poucas 
têm o segundo e o terceiro filhos e pouquíssimas chegam a ter filhos de ordem superior a três. A proporção de mulheres da coorte sintética sem filhos ao final do período de dez anos varia entre $45 \%$ e 50\% em todos os anos das três séries, proporção superior à encontrada na população real.7 Assim, a medida é subestimada e não passível de comparação com as demais. Essa deficiência do indicador mascara o que poderia ser chamado de "efeito idade". O Gráfico 5 indica valores inferiores à unidade para as séries calculadas com dados dos três censos, com pico na década de 1980.

A série de PADTFR, medida controlada por idade, parturição e duração, e a série de PATFR $_{\text {ajustada, }}$ controlada por idade e parturição e ajustada para o efeito tempo (modelo K-O), são apresentadas no Gráfico 6. A comparação entre as medidas definidas como livres dos efeitos tempo e parturição indica que pelo menos uma delas sofre algum tipo de limitação ou é sensível às flutuações nos dados.

GRÁFICO 5

Taxa de fecundidade total por parturição e duração (PADTFR)

Brasil - 1976-2000

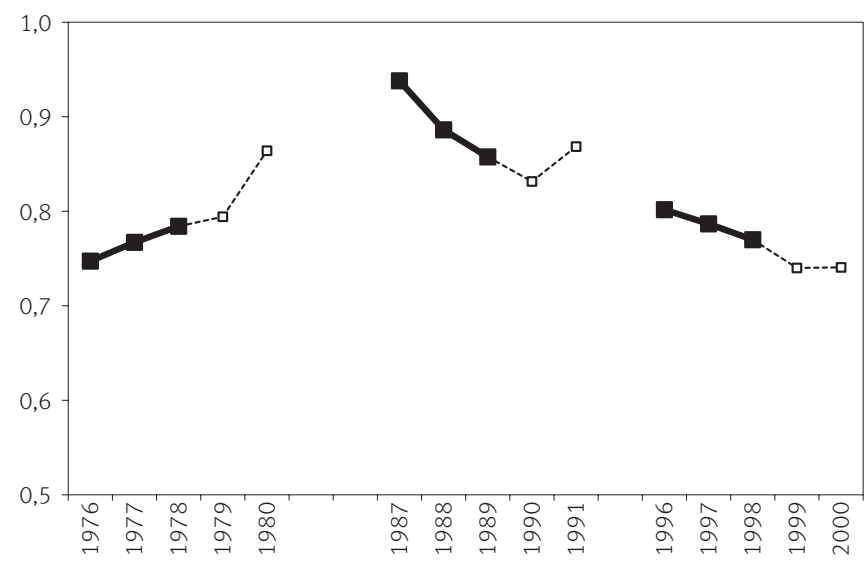

Fonte: IBGE. Censos Demográficos de 1980, 1991 e 2000.

\footnotetext{
${ }^{7}$ Entre a população feminina de 15 a 49 anos, o percentual de mulheres sem filhos era de cerca de 38,5\% em 1980, 34\% em 1991 e aproximadamente $30 \%$ em 2000 , de acordo com os respectivos censos demográficos.
} 
GRÁFICO 6

Taxa de fecundidade total controlada por idade, parturição e duração (PADTFR) e taxa de fecundidade total controlada por idade e parturição ajustada (PATFR ajustada $)$

Brasil - 1976-2000

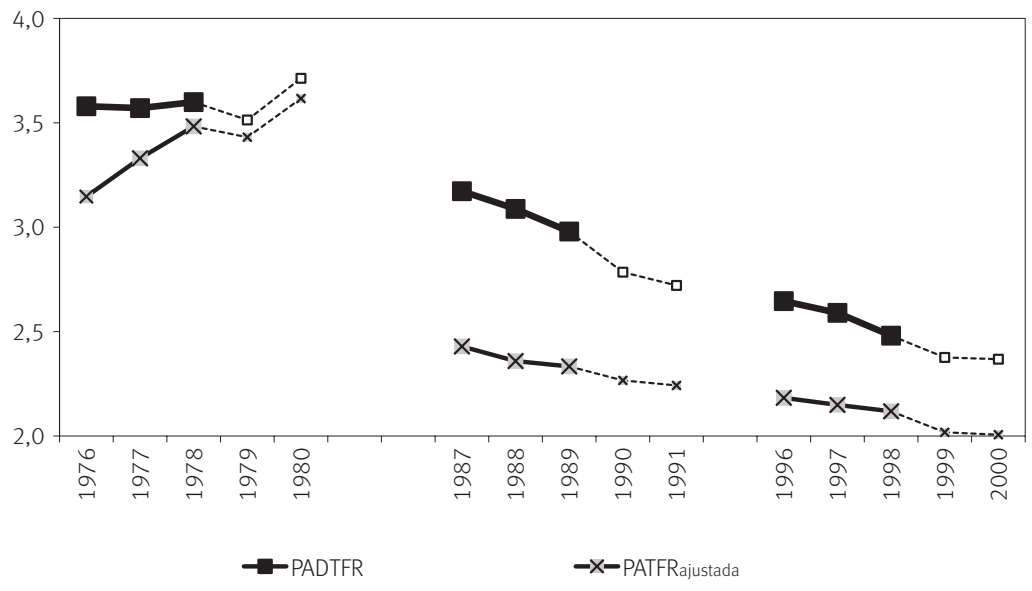

Fonte: IBGE. Censos Demográficos de 1980, 1991 e 2000.

\section{Séries de medidas para fecundidade acumulada até 30 anos de idade}

A limitação das bases de dados para o cálculo dos indicadores baseados na duração desde o evento anterior compromete a análise dos resultados, uma vez que não é possível determinar em que grau a limitação os afeta. A utilização de séries destes indicadores, considerando a fecundidade acumulada até os 30 anos de idade, é uma solução na tentativa de diminuir o efeito da censura dos dados, pois a maior parte do período reprodutivo das mulheres que têm até 30 anos de idade nos anos que compõem a série estará coberta nas histórias de nascimentos. Além disso, no caso brasileiro, até os 30 anos de idade uma proporção significativa das mulheres já completou sua fecundidade. Uma vez retirada a influência da limitação dos dados, os indicadores controlados por duração tornam-se comparáveis aos demais.

Entre os indicadores baseados na duração, o que mais interessa neste trabalho é a PADTFR, porque, conceitualmente, é uma medida livre dos efeitos tempo e parturição, como a PATFR $_{\text {ajustada }}$ do modelo K-O. O Gráfico 7 mostra que, para a série de fecundidade acumulada até 30 anos de idade, as duas medidas estão mais próximas do que para a série completa (até 49 anos de idade), apresentada no Gráfico 6, indicando que parte das diferenças era devida à censura dos dados. Observa-se uma tendência de aproximação das curvas ao final dos três períodos, o que pode indicar que ambas as medidas são mais acuradas nos anos mais próximos ao ano de realização dos censos. Em termos de tendência, a curva da PADTFR aponta uma queda mais suave a partir dos anos 1980. 


\section{GRÁFICO 7}

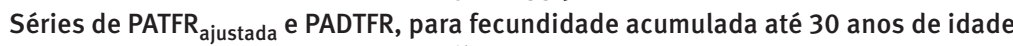
Brasil - 1976-1998

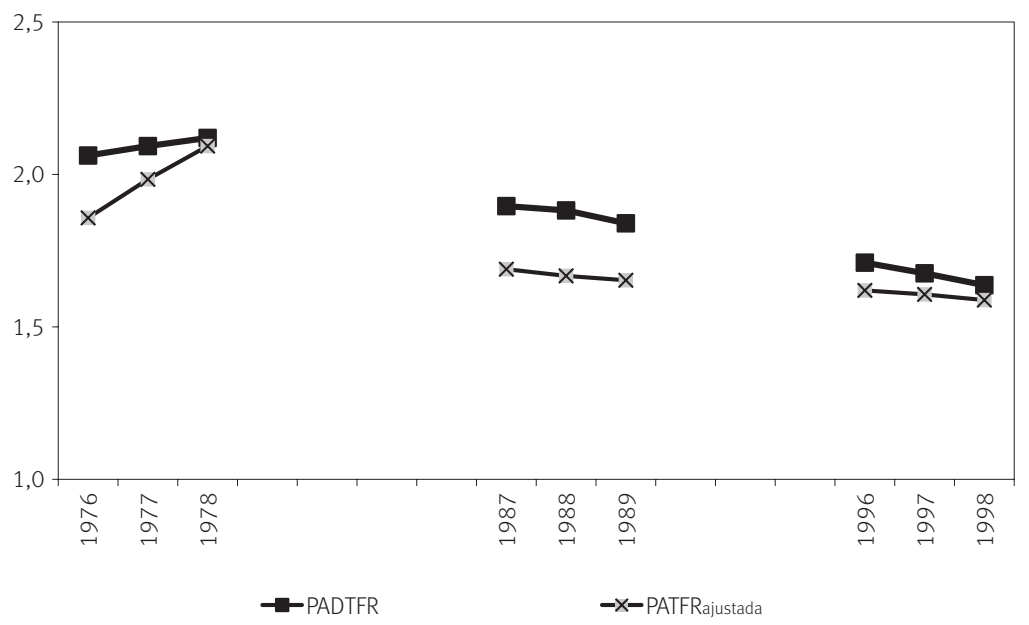

Fonte: IBGE. Censos Demográficos de 1980, 1991 e 2000.

A análise dos efeitos tempo e parturição a partir das novas medidas pode ser feito comparando-se as séries PATFR e PADTFR e as séries TFT e PATFR, respectivamente. Diferentemente do modelo K-O, neste caso não é objetivo mensurar os efeitos, mas apenas analisar as tendências e comparar com os resultados descritos para o modelo K-O. Comparando as séries TFT e PATFR, verifica-se que o efeito parturição atuou no sentido de inflar a fecundidade observada, pois a série da PATFR - a taxa de fecundidade livre do efeito parturição - tem valores inferiores durante todo o período. Para a série do Censo de 1991, a diferença praticamente inexiste. Esse resultado corrobora, exceto para o final da série de 2000 , os resultados encontrados pelo modelo K-O, mostrados pelos Gráficos 1 e 2 .

Ao se compararem as curvas da PATFR e da PADTFR - medidas livres do efeito parturição -, é possível analisar a atuação do efeito tempo. Ao final da década de 1970, a PADTFR possui valores que estão abaixo daqueles referentes à PATFR. Isso indica que, não fosse o efeito tempo, a fecundidade seria um pouco menor que a observada. Em outras palavras, o efeito tempo atuou no sentido de inflar a fecundidade observada. Ao final da década de 1980, verifica-se, ainda, a mesma tendência, mas a diferença entre a PATFR e a PADTFR é próxima de zero. Ao final dos anos 1990, a tendência se inverte e a medida livre dos efeitos parturição e tempo (PADTFR) passa a ser maior que a medida livre do efeito parturição, mas sofre o efeito do tempo (PATFR). Em outras palavras, o efeito tempo passa a atuar no sentido de diminuir a fecundidade observada. Os resultados do modelo K-O (Gráfico 1) são diferentes, embora insinuem uma futura reversão do efeito tempo - ainda negativo para a série completa de 1991 e próximo de zero ao final da série de 2000. 


\section{GRÁFICO 8}

Séries de TFT, PATFR e PADTFR, para fecundidade acumulada até 30 anos de idade Brasil - 1976-1998

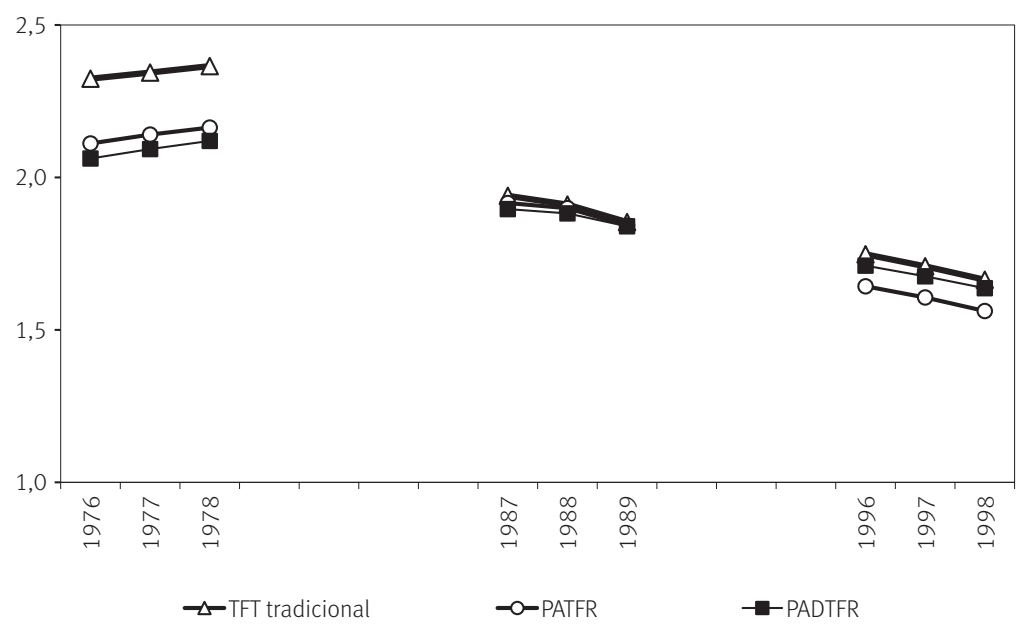

Fonte: IBGE. Censos Demográficos de 1980, 1991 e 2000

O Gráfico 9 mostra as séries de TFT e TFT PPR para a fecundidade acumulada até 30 anos de idade. Curiosamente, a TFT PPR para essa série é maior do que para aquela completa, até os 49 anos de idade. A explicação para tal diferença está relacionada ao fato de que a medida não é controlada por idade e que, até os 30 anos, as probabilidades de as mulheres terem filhos são maiores que até os 49 anos. Os resultados do Gráfico 9 fazem pouco sentido quando se analisa uma coorte sintética de período acumulando-se até os 30 anos de idade.

GRÁFICO 9

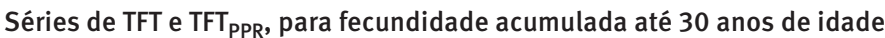
Brasil - 1976-1998

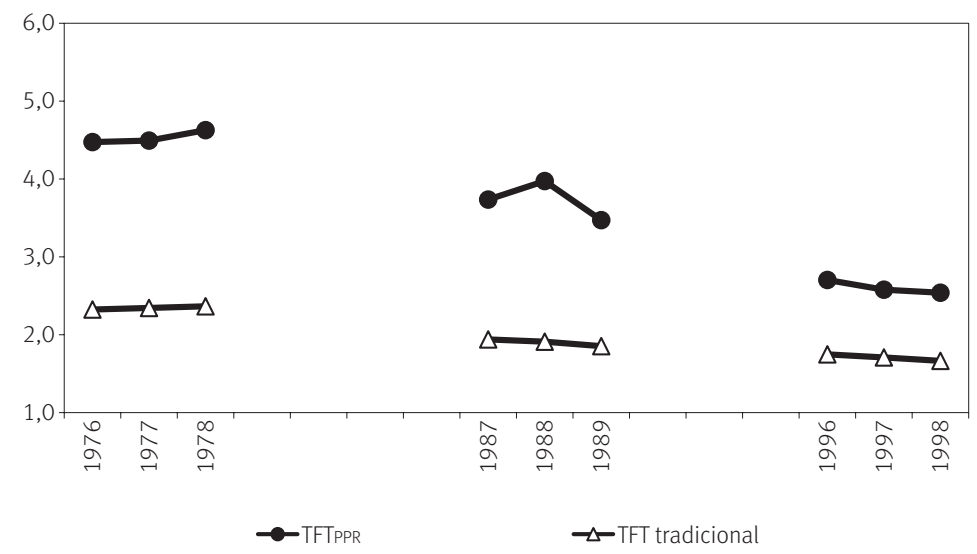

Fonte: IBGE. Censos Demográficos de 1980, 1991 e 2000 


\section{Considerações finais}

Este artigo teve como objetivo calcular e comparar diversos indicadores de fecundidade de período, focando a atenção naqueles que, de alguma forma, buscam corrigir distorções provocadas pelas mudanças na função de fecundidade da TFT observada em determinado período. Mais que uma aplicação às bases de dados de histórias de nascimentos, buscou-se situar o Brasil em relação ao atual debate sobre tempo e quantum.

O debate não é novidade nos países europeus. Desde os anos 1970, a postergação dos nascimentos tem sido uma das características mais marcantes da fecundidade e, como resultado, a taxa de fecundidade total tem sido sistematicamente diminuída, levando alguns países a uma fecundidade observada extremamente baixa (SOBOTKA, 2004). O Brasil, ao final da década de 1990, chegava a níveis de fecundidade próximos ao de reposição, vindo de uma tendência anterior de queda na idade média da fecundidade, o que implicava um aumento da fecundidade observada. É certo que existe um limite biológico para a postergação e o adiantamento dos nascimentos e, mesmo que fatores externos não influenciem, há um momento em que esse processo tem, no mínimo, que cessar. A questão é saber quando isso vai acontecer.

Os resultados da aplicação do modelo K-O mostram que, no Brasil, a transição da fecundidade para baixos níveis foi acompanhada, durante praticamente todo o período de análise, por um efeito tempo negativo e um efeito parturição positivo, o que significa que a taxa de fecundidade total observada foi inflada pelo adiantamento no nascimento dos filhos e pelo aumento da participação relativa das primeiras ordens de nascimento na composição da fecundidade. Isso equivale a dizer que, se não fossem as mudanças da idade média da fecundidade e da composição da fecundidade segundo a parturição, a fecundidade observada seria menor. Ao final da década de 1990, ambos os efeitos estão próximos de zero. Do ponto de vista do efeito parturição, esse resultado indica que a queda das taxas de fecundidade das ordens superiores ocorre na mesma proporção que a redução das taxas das ordens inferiores (no caso, obviamente, de continuidade de queda da fecundidade), ou seja, não há alteração na composição da fecundidade segundo a parturição. Em termos do efeito tempo, o resultado indica que a idade média da fecundidade permanece constante.

Em relação aos indicadores alternativos, é possível observar diferenças entre os resultados encontrados no modelo K-O e na comparação entre a PATFR e a PADTFR, no caso do efeito tempo, e entre a TFT e a PATFR, para o efeito parturição. A despeito das diferenças e da acurácia de cada medida, a tendência é semelhante.

No modelo K-O, observa-se um efeito tempo negativo durante praticamente todo o período, mesmo considerando os resultados do Censo Demográfico de 1980. Ao final do período, o efeito tempo está próximo de zero. Na comparação entre PATFR e PADTFR, o efeito tempo passa de negativo, no início do período de análise, para positivo, no final. Se os resultados do modelo K-O estiverem corretos, o Brasil está próximo de entrar no processo de postergação da fecundidade. Se os resultados mostrados para a PATFR e PADTFR estiverem 
corretos, as mulheres brasileiras, ao final da década de 1990, já estavam postergando o nascimento de seus filhos. Qualquer que seja a situação mais próxima da realidade, é evidente a reversão da atuação do efeito tempo sobre a fecundidade no Brasil, significando que a taxa de fecundidade observada diminuirá em função do adiamento do nascimento dos filhos. Em relação ao efeito parturição, os resultados do modelo K-O e da comparação entre as séries TFT e PATFR mostram a mesma tendência, exceto para o final da série de 2000. Em ambos os casos, o efeito atuou no sentido de inflar a fecundidade observada.

Se o quadro que está se desenhando for confirmado, o Brasil passará de uma situação na qual a taxa de fecundidade total observada é inflada para outra na qual a taxa de fecundidade total observada é diminuída, principalmente pela ação do efeito tempo. Suponha-se uma situação em que a medida pura de fecundidade - quantum puro (PADTFR ou PATFR ajustada $_{\text {) }}$ - no Brasil se estabilize em torno de 2 filhos por mulher. Um efeito tempo negativo durante um período agiria no sentido de diminuir a fecundidade observada. No caso de uma queda continuada do quantum para níveis abaixo de 2 filhos por mulher, a queda da fecundidade observada seria ainda maior e, dependendo do valor alcançado, o efeito tempo poderia levar o Brasil a níveis bastante baixos de fecundidade. O efeito parturição, em ambos os casos, poderia acentuar a queda da fecundidade observada, se for positivo, ou não provocar efeito algum, se for nulo.

A queda da fecundidade observada, a princípio, não significa que as mulheres não irão recuperar essa fecundidade atrasada no futuro, mas certamente o número de nascimentos cairá bastante durante um período posterior ao início da postergação. No limite, o Brasil pode entrar no que Ortega e Köhler (2002) denominam de "efeito do envelhecimento da fecundidade", que é a queda no nível da fecundidade das mulheres que não recuperam os nascimentos adiados. Independentemente da confirmação do quadro, é certo que esses aspectos não podem ser negligenciados na análise da fecundidade.

Há que se considerar, ainda, que os resultados apresentados refletem o comportamento do país como um todo. Se, para o conjunto das mulheres brasileiras, o comportamento dos efeitos tempo e parturição indicam mudança de tendência, isso significa que, para alguns grupos de mulheres, essa mudança já ocorreu. Do mesmo modo, para outros grupos de mulheres essa é uma realidade mais distante. Isso deixa claro que a exploração das bases de dados sobre histórias de nascimentos foi apenas iniciada e que existe uma série de estudos a serem desenvolvidos, a fim de complementar os resultados apresentados e enriquecer ainda mais os estudos futuros sobre fecundidade. Não era objetivo deste artigo esgotar as possibilidades de análise. Pelo contrário, buscou-se, na utilização dos bancos de dados criados, a aplicação de medidas alternativas de fecundidade.

\section{Referências}

BONGAARTS, J.; FEENEY, G. On the quantum and tempo of fertility. Population and Development Review, v. 24, n. 2, p. 271-291, June 1998. 
CALOT, G. Relation entre les indicateurs démographiques longitudinaux et transversaus. Population, V. 47, n. 6, p. 1189-1240, 1992.

FEENEY, G.; YU, J-Y. Period parity progression ratios of fertility in China. Population Studies, v. 41, n. 1, p. 77-102, 1987.

FOSTER, A. D. Cohort analysis and demographic translation: a comparative study of recent trends in age specific fertility rates from Europe and North America. Population Studies, v. 44, n. 2, p. 287-315, July 1990.

HINDE, A. Demographic methods. London: Hodder Arnold, 1998.

KEILMAN, N. La translation démographique: des indicateurs du moment aux indicateurs de génération et réciproquement. In: CASELLI, G. et al. (Eds.). Démographie: analyse et synthèse. La dynamique des populations, v. 1, 2001, p. 359-378.

KEILMAN, N. Translation formulae for non-repeatable events. Population Studies, v. 48, n. 2, p. 341 357, 1994.

KOHLER, H.-P., PHILIPOV, D. Variance effects in the BONGAARTS-Feeney formula. Demography, v. 38, n. 1, p. 1-16, 2001.

MIRANDA-RIBEIRO, A. Reconstrução de histórias de nascimentos a partir de dados censitários: aspectos teóricos e evidências empíricas. Tese (Doutorado) - Cedeplar/UFMG, 2007.

MIRANDA-RIBEIRO, A.; RIOS-NETO, E. L. G.; CARVALHO, J. A. M. Reconstrução de histórias de nascimentos a partir de dados censitários: uma análise comparativa de duas metodologias. Revista Brasileira de Estudos de População, v. 26, n. 1, p. 21-35, jan./jul. 2009.

NI-BHROLCHAIN, M. Period paramount? A critique to the cohort approach to fertility. Population and Development Review, v. 18, n. 4, p. 599-629, 1992.

ORTEGA, J. A.; KOHLER, H.-P. Measuring low fertility: rethinking demographic methods. Rostock, Germany: Max Planck Institute for Demographic Research, 2002. (Working paper 2002-001). Disponível em: 〈http://www.demogr.mpg.de/papers/working/wp-2002-001.pdf〉. Acesso em: 07 abr. 2010.

RALLU, J.-L.; TOULEMON, L. Period fertility measures: the construction of different indices and their application to France, 1946-89. Population, English Selection, n. 6, p.59-94, 1994.

RYDER, N. B. Problems of trend determination during a transition in fertility. Milbank Memorial Fund Quarterly, v. 34, n. 1, p. 5-21, 1956.

. The process of demographic translation. Demography, v. 1, n. 1, p. 74-82, 1964.

Components of temporal variations in American fertility. In: HIORNS, R. W. (Ed.).

Demographic patterns in developed societies. London: Taylor and Francis, 1980, p. 15-54.

SOBOTKA, T. Postponement of fertility and low fertility in Europe. Amsterdam: Dutch University, 2004.

VAN IMHOFF, E.; KEILMAN, N. On the quantum and tempo of fertility: comment. Population and Development Review, v. 26, n. 3, p. 549-553, Sept. 2000. 


\section{Anexo}

Indicadores selecionados de fecundidade de período

\begin{tabular}{|l|l|l|}
\hline Indicador & Descrição & Definição \\
\hline PADTFR & $\begin{array}{l}\text { Taxa de Fecundidade Total controlada } \\
\text { por Idade, Parturição e Duração } \\
\text { (Parity, Age and Duration Total Fertility } \\
\text { Rate) }\end{array}$ & $\begin{array}{l}\text { Medida sintética da tábua de fecundidade, } \\
\text { quando se utilizam as probabilidades de } \\
\text { uma mulher de idade } a \text { ter um filho de } \\
\text { ordem } i \text {, em função da duração, } d \text {, desde o } \\
\text { evento anterior. }\end{array}$ \\
\hline PATFR & $\begin{array}{l}\text { Taxa de Fecundidade Total controlada } \\
\text { por Idade e Parturição (Parity and Age } \\
\text { Total Fertility Rate) }\end{array}$ & $\begin{array}{l}\text { Medida sintética da tábua de fecundidade, } \\
\text { obtida a partir da probabilidade de } \\
\text { parturição de ordem } i \text {, segundo a idade } \\
\text { da mulher. É uma medida livre do efeito } \\
\text { parturição. }\end{array}$ \\
\hline PATFR & $\begin{array}{l}\text { Taxa de Fecundidade Total controlada } \\
\text { por Idade e Parturição (Parity and Age } \\
\text { Total Fertility Rate) ajustada para o } \\
\text { efeito tempo, segundo modelo Kohler } \\
\text { e Ortega (K-O) }\end{array}$ & $\begin{array}{l}\text { Medida sintética da tábua de fecundidade } \\
\text { quando se utilizam as probabilidades } \\
\text { ajustadas para o efeito tempo, de acordo } \\
\text { com o modelo K-O. É uma medida livre dos } \\
\text { efeitos tempo e parturição. }\end{array}$ \\
\hline PDTFR & $\begin{array}{l}\text { Taxa de Fecundidade Total controlada } \\
\text { por parturição e duração desde o } \\
\text { evento anterior (Parity and Duration } \\
\text { Total Fertility Rate) }\end{array}$ & $\begin{array}{l}\text { Medida sintética da tábua de fecundidade, } \\
\text { quando se utilizam as probabilidades de } \\
\text { uma mulher ter um filho de ordem } i, \text { em } \\
\text { função da duração, d, desde o evento } \\
\text { anterior. }\end{array}$ \\
\hline TFTPPR & $\begin{array}{l}\text { Taxa de Fecundidade Total calculada } \\
\text { pela Razão de Progressão por } \\
\text { Parturição (Parity Progression Ratio) }\end{array}$ & $\begin{array}{l}\text { É a taxa de fecundidade total calculada a } \\
\text { partir da probabilidade de parturição de } \\
\text { determinada ordem de nascimento. Não é } \\
\text { função da idade da mulher. }\end{array}$ \\
\hline
\end{tabular}

\section{Abstract}

\section{Quantum, tempo and parity effects in Brazil: period indicators and empirical evidence}

The authors estimate and compare fertility indicators for different periods, focusing on those that correct distortions in the total fecundity rate (TFR) for a given period. The purpose is to raise and evaluate new possibilities of fertility analysis in Brazil. The indicators TFR, TFRPPR, PATFR, PATFRadjusted (K-O), PDTFR, and PADTFR are presented, as well as historical series of tempo and parity effects (K-O model) and mean age at childbearing. The data were taken from a database of birth histories obtained from the 1980, 1991, and 2000 Brazilian demographic censuses. Results show that changes in fertility in Brazil were accompanied by a negative tempo effect and a positive parity effect, meaning that the TFR observed was inflated. In the near future the Brazilian TFR may fall due to tempo effect.

Keywords: Fertility. Tempo effect. Quantum. Birth histories. Brazil.

\section{Resumen}

\section{Efectos tiempo, paridez y quantum en Brasil: indicadores de periodo y evidencias empíricas}

El presente artículo tiene el objetivo de estimar y comparar distintos indicadores de fecundidad de periodo, con enfoque en aquellos que corrigen distorsiones ocasionadas en la tasa de fecundidad total (TFT) observada en determinado periodo, a fin de crear y evaluar nuevas posibilidades de analizar la fecundidad en Brasil. Se presentan series de TFT, TFT PPR, PATFR, PATFR $_{\text {ajustada }}($ K-O), PDTFR y PADTFR, 
así como las series históricas de los efectos tiempo y paridez y de la edad promedio de la fecundidad. Se utilizaron bancos de datos sobre historias de nacimientos, obtenidos a partir de las ediciones de 1980, 1991 y 2000 del Censo Demográfico brasileño. Los resultados muestran que en Brasil la transición de la fecundidad fue acompañada, durante prácticamente todo el periodo de análisis, por un efecto tiempo negativo y un efecto paridez positivo, que actuaron en el sentido de inflar la fecundidad observada. En el futuro próximo, la fecundidad observada en Brasil deberá disminuir, principalmente debido a la acción del efecto tiempo positivo.

Palabras clave: Fecundidad. Efecto tiempo. Quantum. Historia de nacimientos. Brasil.

Recebido para publicação em 16/03/2011

Aceito para publicação em 28/07/2011 